This item was submitted to Loughborough's Research Repository by the author.

Items in Figshare are protected by copyright, with all rights reserved, unless otherwise indicated.

\title{
Understanding undergraduate disengagement from mathematics: addressing
} alienation

PLEASE CITE THE PUBLISHED VERSION

http://dx.doi.org/10.1016/j.ijer.2015.10.006

PUBLISHER

(c) Elsevier

VERSION

AM (Accepted Manuscript)

\section{PUBLISHER STATEMENT}

This work is made available according to the conditions of the Creative Commons Attribution-NonCommercialNoDerivatives 4.0 International (CC BY-NC-ND 4.0) licence. Full details of this licence are available at: https://creativecommons.org/licenses/by-nc-nd/4.0/

\section{LICENCE}

CC BY-NC-ND 4.0

\section{REPOSITORY RECORD}

Solomon, Yvette, and Tony Croft. 2019. "Understanding Undergraduate Disengagement from Mathematics: Addressing Alienation”. figshare. https://hdl.handle.net/2134/20143. 


\title{
Understanding undergraduate disengagement from mathematics: addressing alienation
}

\author{
Yvette Solomon $^{1}$ (Corresponding Author) \\ Tony Croft ${ }^{2}$
}

1. Education and Social Research Institute, Manchester Metropolitan University, Brooks Building, Birley Campus, 53 Bonsall Street, Manchester M15 6GX, UK

Tel. 0161247 2567, email: y.solomon@mmu.ac.uk

\section{Mathematics Education Centre, Loughborough University, LE11 3TU, UK}

Tel. 01509 223185, email: a.c.croft@lboro.ac.uk

\begin{abstract}
This paper explores the phenomenon of student disengagement from university mathematics through the lens of Marx's concept of alienation. Distinguishing between alienation as an objective relationship and the subjective state of disaffection, it argues that dominant modes of teaching in the English school system produce alienated relationships with mathematics, including among successful students, which university teaching does not necessarily reverse. Drawing on interviews with 15 second-year mathematics single major students from 4 universities, in which they explain their experiences of university mathematics, we argue that 'undoing' alienation and enhancing engagement at university rests on the development of new relationships with mathematics through greater support for students' developing confidence in independent mathematical judgement.
\end{abstract}

\section{Introduction: undergraduate disengagement from mathematics}

Student disengagement from undergraduate mathematics in the UK is widely reported (Croft \& Grove, 2015), raising basic questions as to how well qualified students who report high levels of confidence and enjoyment at school can become so disillusioned with a subject which they have actively chosen to study at university. Explanations vary in terms of the assumed locus of the problem and the respective roles of the individual student and their social context. One area of debate focuses on the extent to which students are prepared for university-level study in terms of their mathematics skills and knowledge (Smith, 2004; Hawkes \& Savage, 2000); while this is a somewhat deficit model, research which emphasises lack of exposure to proof highlights issues of form or practice as well as content (Harel \& Sowder, 2007; Healy \& Hoyles, 2000). Focusing less on deficit and more on learner identity, other accounts consider socio-emotional context in terms of the negative effect of the transfer from small classes and close teacher-student contact at school or college to impersonal lecture-based teaching (Wiliam, 2005). On a related theme, relationships with peers and with tutors can be a critical factor in whether or not students express positive attitudes to university study (Solomon, Lawson \& Croft, 2011). While Mathematics Support Centres were primarily introduced to provide support for learning in terms of content, Solomon, Croft \& Lawson (2010) reported that the spaces that such centres provided had the potential to 
generate a collaborative ethos which went beyond emotional support to incorporate perceptions of mathematics as a constructive and participative endeavour. This focus on developments in students' understanding of the nature and practice of mathematics (as opposed to just its content) is also suggested in dispositional accounts such as Daskalogianni and Simpson's (2002) study of mismatch between students' school-based beliefs about mathematics and their experiences of university mathematics. Their work suggested that failure to reconcile such a mismatch often leads to disillusionment and 'cooling off'.

Collecting these themes together, we suggest that students' relationships with mathematics in terms of their understanding of the nature of mathematics and their self-positioning within mathematics as a developing body of knowledge is what underpins engagement and disengagement: it is not just a matter of ability. This is not a new idea, and it is particularly well researched at school level, where the impact of traditional transmissionist teaching practices on understanding and engagement is a major focus (see for example Boaler, 2012). Looking more closely at teaching and learning practices, Pampaka, Williams, \& Hutcheson (2012) reported that being positive about transitions into university mathematics was negatively associated with transmissionist teaching at university. Turning to university study itself, research which focuses on students' relationships with mathematics has found that students' understandings of the nature of mathematics are central to their attitudes to and expectations of undergraduate study and to their sense of 'belonging' and community in university departments (Biza, Jaworski, \& Hemmi, 2014; Jaworski \& Matthews, 2011; Jaworski et al, 2012; Solomon, 2006, 2007).

Why all this matters is summarised succinctly by Schoenfeld (1994):

When mathematics is taught as received knowledge rather than as something that (a) should fit together meaningfully and (b) should be shared, students neither try to use it for sense-making nor develop a means of communicating with it. (p. 57)

We will argue that it is these twin outcomes that underpin alienation and in turn disengagement, because neither recognises that mathematics is

a living, breathing discipline in which truth (as much as we can know it) lives in part through the individual and collective judgments of members of the mathematical community. ... Mathematical authority resides in the mathematics, which-once we learn how to heed it—can speak through each of us, and give us personal access to mathematical truth. (p. 68)

Thus the development (or not) of a sense of personal access to mathematical truth conviction based on participation in the practices of the mathematical community - can be seen as dependent on how far undergraduate teaching is able to counteract a strong likelihood of a legacy of school teaching which emphasizes mathematics as already created rather than mathematics in creation, In the following section, we develop a conceptualisation of the impact of mathematics as received knowledge through the lens of alienation, with a view to understanding better how and why students might become disengaged from university mathematics.

\section{Conceptualising alienation from mathematics}

As many commentators note, school mathematics largely favours didactic teaching of algorithmic approaches applied by the individual learner to find answers validated by the 
teacher's or text book's authority. In England, where this study took place, this approach is clearly exacerbated by the marketization of education since the 1980's and the employment of technologies of accountability which privilege the easily measurable (Exley \& Ball, 2013) and generate an emphasis on the exchange value of education (Williams, 2011). Critics of this system have pointed to the deleterious effect of pedagogic practice which 'teaches to the test' rather than giving time to building understanding, leading to rising levels of disaffection particularly in the later years of secondary schooling (Boaler, 2015). However, we want to draw attention here to the need to distinguish between disaffection and alienation; doing so enables us to see how students who are successful and who like mathematics might be understood as alienated and consequently vulnerable to disengagement. To illustrate this, we examine Boaler and Greeno's (2000) analysis of student identities in the light of Marx’s theory of alienation which, we argue, provides a more sensitive tool for understanding students' relationships with mathematics.

Boaler and Greeno's (2000) study of advanced calculus classes in six Californian high schools found that although all the students were in a position to progress further in the subject, differences in their descriptions of their classroom experiences corresponded with their beliefs about the nature of mathematics and their desires to study it further. Classes in four of the schools were characterised by individualistic didactic approaches to learning in which students practiced procedures demonstrated by their teachers. Classes in the remaining two schools were characterised by collaborative approaches, and teachers encouraged student discussion when explaining methods. Boaler and Greeno found that students in more didactic classes took up a passive role in relation to mathematics, as something predetermined and unavailable to discussion; success required that their goal was to memorise and be positively evaluated by the teacher or the textbook. While they were highly successful in learning the rules, half of these students disliked mathematics and slightly less than half (generally the same students) did not intend to study it further. Their rejection was based on the lack of opportunity to develop the kind of understanding they sought, and their feeling that studying mathematics ran counter to their sense of self as creative - they rejected mathematics because it did not fit the kind of person they wanted to be. Boaler and Greeno call these students alienated, in contrast to the remaining half of the students who liked mathematics precisely because of the way that their classes positioned them as received, or passive, knowers. Students in collaborative discussion-based classes took an active role in relation to mathematics, as a 'field of inquiry'. Their goal was to understand its concepts as constructed in interaction with other people, texts and representations; almost all said they enjoyed mathematics, with 80 per cent saying that they planned to continue. For these students, their relationship with mathematics resonated with their views of themselves as 'verbal' or 'thoughtful' agents: they were 'asked to contribute to the judgement of validity, and to generate questions and ideas ... [they were] given more agency' (p. 189).

Boaler and Greeno's (2000) suggestion that students who rejected mathematics in their didactic classes were alienated, whereas (by implication) those who did not reject it were not, only holds if alienation is taken to refer to a subjective state of feeling alienated. However, Marx's conceptualisation of alienation suggests otherwise; it captures multiple relationships of being which when applied to mathematics draw attention to our relationships to the activity of doing mathematics itself, to the product of that activity, to others who are engaged in the activity, and to our own sense of self. In this formulation, alienation indicates an objective (not a subjective) relationship, and applies to all students in so far as they are separated from:

1. the activity of mathematics itself (by their subjugation to memorised rules); 
2. its product (in terms of the dominance of the exchange value of mathematics qualifications over the use value of its practices);

3. their fellow students and others in the mathematics community (by their isolation and competitive relationships); and

4. themselves (in terms of their dependence on the teacher or textbook to say they are right).

Like Marx and Engels' propertied classes (the 'winners' in the class system), students who embrace a didactically taught mathematics (and are 'winners' in that sense) are nonetheless alienated:

The propertied class and the class of the proletariat present the same human selfestrangement. But the former class feels at ease and strengthened in this selfestrangement, it recognises estrangement as its own power and has in it the semblance of a human existence. (Marx \& Engels, 1845, p.36)

Students who are successful in a system which rewards right answers produced at speed and without much understanding may well feel confident and at ease, gaining from a sense of doing better than others. Once at university, where they encounter the well-documented 'step up' and its associated difficulties (a new experience for many), some university students continue to be happy not to understand, 'as long as they can do it', dismissing proof, for instance, as unimportant if it is not assessed (Solomon, 2006, 2007). Even so, they are alienated according to this analysis, since they work without agency and ownership, a situation aggravated by the fact that many enter university to study mathematics for extrinsic reasons, having been coached in its exchange value in a competitive market. As Williams (2012, p. 65) argues, 'this competition with others ultimately alienates the learner from other learners and even from their own learning and so from themselves'. Other students find that their experience at university results in a sense of disconnection from mathematics (Solomon, 2007). Equally alienated, they are particularly conscious of the separation of mathematics from their own powers and capacities - they are 'the plaything of alien powers' (Marx, 1843, p. 220), and conscious of their loss:

... the object which labour produces - its product - stands opposed to it as something alien, as a power independent of the producer ....this realization of labour appears as loss of reality for the worker; objectification as loss of the object and bondage to the object, and appropriation as estrangement, as alienation' (Marx, 1844, p. 324)

Marx's conceptualisation of alienation as an objective relationship explains our responses to school and university mathematics in a more nuanced way than Boaler and Greeno's 'common sense' ordinary language usage of alienation as an expression of subjective feeling. Specifying as it does how separation takes many forms - from the activity, from the product, from others, and from ourselves - it captures the contrasts between received and connected knowing that Schoenfeld draws, and the idea of personal access to truth based on community values. In so doing, it also explains how students might come to disengage from university mathematics, either because it disappoints or threatens their perceived need to always succeed or be the best, or because it fails to let them into its secrets while demanding that they are subject to its rules.

Pursuing these ideas in this paper, we explore undergraduate students' relationships with mathematics in terms of the expression of alienation in their accounts of their experience of entering undergraduate study and the challenges it presents. We focus in particular on three research questions: RQ 1: How do students understand and relate to the activity and the product of university mathematics? RQ 2: How do they position themselves in relation to 
mathematics as a community endeavour? RQ 3: How do they describe university teaching as a support for personal access to mathematical meaning-making and mathematical truths?

\section{Methodology}

Prompted by research documenting student dissatisfaction with access to understanding at high school (Boaler \& Greeno, 2000) and at undergraduate level (Solomon, 2007), the study on which this article is based was designed to explore how students described the nature of 'understanding' in university mathematics, the benchmarks or standards they employed in evaluating such understanding, and the role of the university in enabling access to processes of knowledge justification. We interviewed 15 students (6 women, 9 men), who responded to a request for volunteers appended to a survey questionnaire circulated among second-year students in 4 universities including 2 post-1992 'new' teaching-focused universities (hereafter U2 and U4) and 2 research-intensive universities (hereafter U1, U3). This was a selfselecting sample whose inclusion in the study was based on their availability for interview: some students initially agreed to interview but did not reply to subsequent emails - we interviewed all who replied. All were studying mathematics either as a single major bachelor degree or as a four-year master of mathematics. The interviews were conducted by three different researchers (including the first author), none of whom were involved in teaching these particular students. The interview itself was semi-structured around key topics within which interviewers would work with prompts and questions to follow up students' responses. Our key topics covered students' assessment of how they were progressing and the design of their courses, their assessment of their competence and understanding in calculus (we chose calculus as a common denominator topic which all students would have been dealing with in their courses), how they identified their own understanding of a topic and how they would go about learning a new topic, contrasts with mathematics at school/college, and their current feelings about the subject. All interviews were audio recorded with students' permission, and fully transcribed and anonymised.

The data gathered thus presented a fairly complex narrative for each student. Analysis began with a process of reading and re-reading the transcripts to identify recurring themes in what students told us about their experiences; this first analysis stayed close to the key topics in the interview, and focused on similarities and differences between students while retaining an overview of each story as a whole. In order to address our research questions, we moved to a second stage of analysis which brought these similarities and differences together within the conceptualisation of alienation developed above. We focused on the four aspects of alienation in terms of students' relations with mathematics, operationalised as described in Table 1.

\begin{tabular}{|l|l|}
\hline Relation with.... & Operationalised in terms of... \\
\hline The activity of mathematics & $\begin{array}{l}\text { Comments about the nature of mathematics at school/college } \\
\text { and university: rules, proof, calculation, theory }\end{array}$ \\
\hline The product of mathematics & $\begin{array}{l}\text { Comments about the point of doing mathematics, students' } \\
\text { aims and expectations, and what their work is for }\end{array}$ \\
\hline Others in the community & $\begin{array}{l}\text { Comments about comparison with others, competitiveness, } \\
\text { collaboration, participation }\end{array}$ \\
\hline The self & $\begin{array}{l}\text { Comments about conviction, proof, teacher authority, } \\
\text { confidence }\end{array}$ \\
\hline
\end{tabular}

Table 1: Operationalisation of aspects of alienation in mathematics 
In the following analysis, we address our research questions with reference to students' relations with (1) the activity and (2) the product of university mathematics [RQ1]; (3) their relations with others and the self in the context of their self-positioning within university mathematics [RQ2]; and (4) their relations with all four aspects of alienation in terms of their role as learners in the university [RQ3].

\section{Analysis}

While the various aspects of alienation are clearly interlinked and overlapping, students' relations to the activity of doing mathematics are most clearly seen in their accounts of the contrast between school and university, while their relations to the product of mathematics are most evident in what they say about the nature and value of understanding and what they expect to gain from their study. We focus on these two issues first in our analysis. We then explore students' accounts of their relations to others and to themselves as evidenced by what they say about their sense of ownership and participation in mathematics and its practices. Finally, we look closely at what they say about the role of university teaching in their development as mathematicians with multiple relations to activity, product, self and others.

\subsection{The nature of mathematical activity: contrasting school and university}

The majority of students expressed their relation with the activity of mathematics in terms of a stark contrast between school and university mathematics; at school they had largely been positioned as passive receivers of knowledge, divorced from the activity of mathematics. This was articulated by some students in terms of a sudden appearance of 'theory' at university, as Laura (U1) does here, contrasting her calculation-based school study with the university demand 'to understand the theory behind the maths':

\footnotetext{
.. it's a lot more theory based at university ... at A Level it was more calculation or so. I think the transition was difficult because it was more a definition ... you needed to know your definitions, you needed to learn the theorems, and I think that was quite difficult to get your head around, whereas at A Level you're just used to being given say numbers and say integrate or differentiate, whereas now we need to know the definition of integration ... I think at the beginning for a lot of people it was difficult to make that transition to understanding the theory behind the maths rather than just the basic numbers...
}

Laura had expected university mathematics to be difficult but hadn't realised that the source of the difficulty would lie in a change in the nature of mathematical activity from learning disconnected rules to engaging with what lay behind them:

So we were asked to solve problems that involved numbers, like "differentiate this function” or "integrate this function". But then we were asked to prove certain expressions as well. So ... instead of just knowing that for example $\mathrm{x}^{2}$ differentiates to $2 \mathrm{x}$, we had to use the definition to prove that. So you actually get an insight into where it all comes from ... which kind of links up a lot of the stuff from A Level where we didn’t really understand where it came from, you just had it as a rule.

Hardika, at U3, describes the change as a need to 'think outside the box':

A Level was like um ... I don't know it's like computation - you know exactly what you'll have to do. ... They give you a method and you just have to apply it. Whereas here it's like proving things, you have to think outside the box, and it's a big jump from A Level to uni ...

Esther (U1) makes the same observation as Laura about theory, but is clearly negative about the change, which she sees as introducing a different mathematics from the sort that she wants to do:

Um, it's a lot of theoretical maths, so it's completely different to school work. School you were using equations and thumping numbers in and getting the answer - here it's a lot of theory behind the maths and how to prove it. Not so much calculation which is not what I like. ... I could sit down for hours 
and work out the turning points on all sorts of graphs and stuff. ... here the maths is very different, it's very theoretical. ... I'm not a massive fan of that.

Esther's lamenting of the withdrawal of mathematics as a rule-bound calculation activity with the sole purpose of getting right answers seems to indicate how she has embraced "estrangement as its own power", to quote again from Marx and Engels (1845, p.36). While she is dissatisfied with her loss, other students describe university mathematics as a shock, raising questions for some about their imagined future selves. For Emma (U3), the change destabilised her study plans, and left her separated from the activity of mathematics in her lack of understanding and isolation:

... I think it is just a big change from school and you don't realise until you get here. Like within a couple of weeks I nearly changed course, because it just shocked me. And you feel like everyone else understands. Whether they do or not ...

We can understand these accounts as indicative of alienated but untroubled and untroubling relationships with mathematics at school which, however, become disturbed and more obvious at university. Students respond in different ways, some negative, some positive; while some continue to hold on to earlier sources and modes of understanding, others detect and move towards new, more connected, relations with mathematics.

\subsection{The product of mathematical activity: the value of understanding}

Laura's (U1) comments on calculation versus definition/theory led her to describe the point of university mathematics as making valuable connections that she had not been equipped to make at school:

The calculus problems sort of put everything into one ... it made sense. Like you knew why $\mathrm{x}^{2}$ differentiated to $2 \mathrm{x}$ by definition - which was quite good. And we had a lot of problems that were proofs or recalling theorems and ... you had to use certain theorems in certain ways. So the problems sort of intertwined everything all together.

This is important to her, since she identifies herself as a certain kind of person in her relation to mathematics:

I am the kind of person that likes to know why I'm doing something. I mean the first step is obviously understanding the rule and being able to answer questions that are given. But then after that there does come a point where you want to know why that works. ... [it] often makes more sense when you know the theory behind it, rather than just ... that you can apply the rule - I think it's important to know the theory behind it.

James (U2) also seeks to understand what lies behind new concepts, in terms of finding applications:

If I come across something that I don't fully understand or can’t put into context, I will go out of my way to put it into context to find where it fits in in an application in process. So with multivariate calculus I haven't found an application for it yet, so ... I will go back and find out where it's used ....

Joe (U3) puts similar ideas in another way, valuing understanding as 'relational':

... if I'm hit with a question, a topic, whatever, I can instantly know where I'm going and understand ... understand the key elements in the question. ... understanding my own understanding in relation to something ... I guess I learn something quite relationally ... I can see all the linking together and where the bits of the question link in and stuff.

Thus these three students describe a desire for a connection to the product of doing mathematics: they want to own and control its power, rather than being subjugated to it. In contrast, both Cristophe and David (U4) aim for a benchmark of being able to solve multiple examples, remaining fixed on the importance of external rather than internal judgements which are therefore separate from themselves. Cristophe is quite emphatic about this: 
C $\quad$... if I can solve a problem that doesn't mean that I completely understand it, that I'm comfortable solving more. It just might be an easy problem, so I need to solve more exercises to see if I definitely understand it or it's just a problem.

I So say you solve lots of problems and you're getting them all correct, for you does that mean that you understand the topic? Is that a good measure?

C Yeah yeah. ..... If I read a question and I ... know exactly what to do, then it means I'm perfectly comfortable with the topic.

David thinks that perhaps understanding underlying concepts is a desirable option, but it isn't 'really important':

at the end of the day, I just want to be able to do it and if they just tell us we can't do the proof right now, I'm like 'Okay, whatever, as long as it's ... as long as I can get on with doing this, like doing what you want us to learn, I guess I don't need to know why it works'. But in a way it can help you to understand the underlying concepts of how and why it works ... of how to use it and when to use it, if you know the proof, but it's ... it's not really important, I don't think.

Students vary, then, in terms of how they relate to both the activity and the product of their mathematical activity. Some notice that the 'goal posts have moved'; as a consequence most (but not all, as in the case of Esther) aspire to a more connected understanding and a sense of ownership. Some seem to see these aspirations as realisable, while others, such as Emma, seem to think it impossible. Others see university as simply covering more, and harder, mathematics, expressing alienated relationships which are more akin to those that the others relish leaving behind.

\subsection{Self and community: owning mathematics}

As Schoenfeld notes, recognising mathematics as meaning-making within a community of collective judgement entails a particular positioning of self within that community. While some students begin to talk about making connections within mathematics, they may struggle to meet this aim, holding on to former models of authority as justification for knowing they are right. This position is encapsulated in David's positioning of his lecturers as essential figures in providing a warrant for being right; he is unable to find conviction otherwise:

... the easiest way would be for me to go to a lecturer with each question that I'm having trouble with ... I only know I'm doing well once I've got the right answer and can check I've got the right answer, I don't know I'm doing well going through the question.

As we have noted, undergraduates have far less contact with lecturers than they have had in the past with their school teachers, and peers take on new importance for many. Another theme in the interviews is agreement with other students as an indicator of 'being right'. There are subtle variations in this theme, however: peers can provide support in the form of help, or they can play a part in building mathematical argument. Carol, at U1, frequently talks about asking others for help when she doesn't understand; here she is talking about how she deals with the unfamiliar:

First thing is I panic. But then it's fine because... I either go and ask my friends if they have seen it so they can explain it. If they can't then I try and research it myself. And if I don't find anything then I come either to the MLSC [mathematics learning support centre] or I email the tutor.

While Carol positions herself as a more or less passive receiver, Esther (U1) talks more about working with other students to develop her understanding:

I'd probably speak to someone else and get their opinion, or explain things to them and get them to explain things to me, and see if our understanding was the same. And obviously we might both be wrong, but in some ways it's probably less likely if there's two people that have the same understanding. 
Although she seems to value mutual explanation, and is arguably on the way to developing independent arguments about what is right rather than depending on tutors' judgement, her assumption about decreasing the likelihood of being wrong suggests that she is nevertheless turning to a final external authority.

However, it is possible to see a shift towards Schoenfeld's idea of the authority that resides in the mathematics itself in some students' accounts. Here, Joe (U3) describes 'seeing connections' which provide a context for 'learning the language of the course', in a way which enables him to speak the mathematics:

... rather than seeing all the isolated definitions and stuff I can actually understand the theme of the course and how everything interlinks and the relationships with everything, and then I'm quite happy. Once I've ... learnt the whole language of the course kind of thing so I can speak it fluently I guess that's when I'm quite happy.

Rob (U1) also talks about taking ownership of the mathematics, this time in terms of connecting to the activity of doing mathematics and its products, through experimentation and application:

The way I understand it - I try to set myself my own questions. Sometimes I don't explicitly write them, but I'll look at a topic and think 'What if I considered it in this way?' So as an example differential equations, I often if I understand the new approaches, because there's many ways to solve them or analyse them, I'll make my own differential equation without knowing how it's going to be solved, and then try to analyse it. So I try to make my own question, analyse it. Or if it's theory I'll try to put that theory into practice somewhere.

Hardika (U3) refers explicitly to the need to convince herself about mathematical truths:

... if you understand it properly and you go through and you like convince yourself it's true and understand it properly, then you can use it in a different module, you can use stuff you've learnt from way back and using all the theory behind other things into this module, so it's useful then.

Charting her development across the previous two years, Holly (U3) explained how she now relied on her own judgement rather than that of her friends, and had matured as a mathematician:

Well I've managed to do well on the problem sheets that have been assessed so far. Obviously we don't get marks for the non-assessed ones. But for example the first term of last year of analysis ... it took me more than a term to get to grips with the sort of proofs that you had to deal with and what you can and can't do, that sort of thing. Whereas with this year, all that sort of basic intuition is more concrete in my mind. So it's better in that respect. And last year - I've never been one to cheat - a lot of people would compare answers a lot and things like that, but I'd discuss the problems more with my friends. Whereas this year I've been finding it more independently.

She gives a reason for this shift in terms of greater familiarity with the nature of mathematical proofs:

I think it's more just once you've seen more maths, you get used to the standard sort of proofs ... like the standard sort of format for proofs. Like this sort of question, I probably will try this first, and that usually works.

She summarises these ideas in terms of maturity, confidence and experience:

Again last year I think I found harder than this year. Simply because... maturity is an odd word to put on it, but... confidence in what you're doing I suppose and experience in university maths. ... so that makes it easier sort of as you go along I think, yeah.

Overall, the students we interviewed fell into a spectrum of dependence/independence in terms of reliance on the external authority of the teacher versus conviction arising from a connection with the authority of the mathematics itself. For some students, aspirations towards new relations with the activity and product of mathematics were complemented by new positioning of self within the community. Others remained outside of (or unaware of) the 
community, positioning themselves as passive receivers of others' knowledge and judgements.

\subsection{University teaching as support for new understanding: undoing alienation?}

Our analysis so far suggests that although some students in our study remained in 'school mode', the majority recognised and embraced the new demands of university mathematics: they commented favourably on the shift in the nature of mathematics and they aspired to a state of ownership which meant they would not only see why mathematics 'works' but also be able to be certain that they were right. How far did the teaching they received support such a move?

A striking feature of the interviews is the extent to which students talk about dips in confidence, and a corresponding dip in their enjoyment of mathematics, accompanied by frustration with themselves and with mathematics. Although this might not be surprising from the point of view that students who were once at the top of the class at school are now potentially at the bottom, our analysis suggests that such dips more importantly reflect a shift in the basis of their confidence. In the past confidence was (falsely) based on others telling them that they were right - as we have argued, this alienated state of being holds as a positive for those who are 'winners' in competitive education. At university, however, they are unsettled by change in the nature of mathematical activity and a corresponding shift in the aim of doing mathematics and indeed the positioning of self within the mathematics community. Thus Esther (U1), who we have seen is negative about the changes and holds on to her previous mode, talks about her confidence 'taking a massive hit'; she still enjoys mathematics, but her major complaint is the frustration of finding that she doesn't understand and is not gaining the marks she feels she should be getting:

\footnotetext{
... I feel like I should be doing a lot better than I am. Which is difficult because I just can't work out why I'm not... for example this year with one of my ... modules ... I'd worked really hard for it and I'd done all the past papers and I studied all the questions, I'd been through all the notes and that, felt like I've really understood it. ... I was really confident, I sat down in the exam, and the paper came out and I just had no idea. And that's what I'm struggling with I think is .. I would be really enjoying it, but then when I can't do the papers... it's really frustrating and it's quite upsetting sometimes... not to be able to do them as well as I'd wanted to be able to do them. ... I'm still enjoying it but not in the same way at all.
}

Despite what she says above about proofs and independence, Holly also talks about a lack of confidence; indeed her opening speech is about how she might not manage to stay on the course. Emma (U3) also says that she is not half so confident now in that she no longer expects to be able to do the mathematics; her expectations about her placing in the overall benchmarking of success have changed radically:

... if you gave me a question now expecting me to be able to do it, I'd expect that I might be able to do it, but I probably wouldn't and then I'd be happy if I could. Whereas before I would be disappointed if I couldn't do it - that's the big change.

Hardika says she no longer really enjoys mathematics, and she's not as good at it now, as does Kathryn, at U2:

It's sort of not as easy. 'Cos I used to find it easy then. I do like finding things out and getting the answers to things, but it's not as fun. So I don't enjoy it, but I like it. I don't dislike it at all, but I don’t enjoy it either. ... sometimes when I've just got an assignment back and it's awful, I just think 'Oh no, why am I doing this?' but in the end I've always been able to carry on with it. So ... okay.

What these students have in common is not just a lowering of expectations - they are now small fish in a big pool - but a new awareness for some of their state of alienation from the activity of doing mathematics; many recognise that there is more to mathematics than they thought at school, but it often eludes them. They may describe themselves as wanting to 
make progress towards understanding and ownership, identifying as mathematicians in Schoenfeld's (1994, p.60) sense - they seek “competence with the tools of the trade, and using those tools in the service of the goal of understanding structure-mathematical sensemaking” - but they also describe the university as failing to support them in this. Rob (U1) gives a rare and enthusiastic description of 'a lot of trying to make you think about the maths yourself':

So we did a lot of 'Can you write this definition? How do you think you should write it?' Looked at typical problems that we could consider. Then extreme cases ... and we were asked to think of extreme cases where theorems may not apply.

This is in contrast with Laura's (U1) more typical complaint of not understanding the purpose of what she is being asked to do:

I look at it and I just don't understand why we're doing what we're doing and where we're going with it. Like in proofs for example sometimes we introduce a particular variable just because that makes the proof work. I don't always understand why that is the case. ... And like I sort of want to know why it's that ...

Emma (U3) also talks about the experience of apparently arbitrary processes:

... I think what I find with a complicated proof is I'll maybe get half way through it and understand, and then they'll say 'Right we'll now assume something else', and I can't follow why they're doing that, and then it goes off into some other tangent that ... to me just seems completely out of it, and I'm like "Well I understood why you were doing the first few steps, but why are you suddenly now going completely in the other direction?" and that's when I lose it, yeah yeah, that's when I completely lose it. And then suddenly they kind of go "End of proof" and I don't see why what they've got to at the end actually proves it. ... So it's ... Frustrating. That's the word.

Laura and Emma locate the source of failure to understand not in terms of in teaching which fails to show how, but in teaching which fails to show why, by-passing mathematical sensemaking with an unexplained short-cut or assumption 'just because that makes the proof work'. Such reproduction of the authority of the teacher is summarised in Hardika's description of the use of 'tricks' and explicit demands for trust in lecturers without understanding:

$\mathrm{H} \quad$ No a lot of the lecturers are just kind of ... my partial differential equation ones it's just like 'Yeah just trust me on this one'. So it's just like 'Okay.'

I Yes, for now you just do what you're told, yes. ...

$\mathrm{H} \quad$ With the little tricks.

It seems that situations such as this do little to support the mathematical aspirations of these students, reconfirming as it does the 'alien power' of mathematics. This is not to say that this is universally true, of course: Rob’s story provides a counter-example, but it is rare.

\section{Conclusion: alienation, ownership and (dis)engagement}

In this paper we have considered the problem of disengagement in terms of the extent to which the experience of university mathematics reverses the alienating effects of much school mathematics pedagogy. We argue that even students who are successful at school and who choose to study mathematics at university are likely to be alienated from it: they are alienated from the activity and the product of mathematics, in terms of their focus on the memorisation of rules and on mathematics as primarily having exchange value; from other students in terms of their positioning within a competitive environment which is focused on grades rather than understanding; and from themselves in the sense that they must rely on others in order to know whether they are right or wrong. Again, while we do not intend to 
state this as a general truth, our data indicate that many students do indeed arrive at university having experienced a largely procedural and algorithmically-driven mathematics which relies on the authority of the teacher as the arbiter of right and wrong: they comment on a shift from calculation at school to a new emphasis on theorising and proof at university, and the shock that this change engenders.

University mathematics is, then, very different in nature from what they have been used to. As they say, it is more about theory than calculation, and some students actively dislike this. But many appear to embrace this change, talking about their desire to understand and engage with mathematics as it is constituted at university. However, our question is whether the kind of teaching that they experience at university enables them to access this different mathematics and engage with it: does university reverse the effects of alienation? Clearly, as we have seen, some students describe moving towards a state of greater ownership of mathematics in terms of a new reliance on their own judgement. Others, however, appear to remain stuck in their former understandings of the nature of mathematics and how to know that they are right. We found that accounts of teaching which supports connections and independent judgement are rare; more commonly, they describe teaching which continues a familiar pattern of teachers who do not explain what they are doing or why - mathematics as a series of 'tricks' continues.

Our findings thus contribute to our understanding of disengagement from university mathematics by providing an analysis of the relationships with mathematics that students bring with them, and which are then disturbed by the shifts they experience. Building on previous research such as Boaler and Greeno (2000) and Boaler (2012), we have shown how students who enjoy more transmissionist teaching can experience a destabilising drop in confidence as they encounter new demands at university. At the same time, we have shown how some students seek to leave old relationships behind but experience frustration at not being supported in the development of new ones. This understanding of their attempt to build new participation in the community of mathematics adds to what we already know about the importance of community and belonging in undergraduate experience and understanding identified by researchers such as Biza et al (2014), Jaworski \& Matthews, (2011), and Jaworski et al, (2012). In particular, it connects students' understandings of the nature of mathematical activity and their access to the power of its production with their positioning in that community by both others and themselves. We suggest that university teaching which supports the development of independent judgement and sense-making is an important component in developing students' sense of ownership of their mathematical knowledge. Without support, even the 'best' students can remain alienated from a mathematics which they feel they do not understand and cannot work with.

\section{References}

Biza, I, Jaworski, B. \& Hemmi, K. (2014). Communities in university mathematics. Research in Mathematics Education, (16)2, pp. 161-176

Boaler, J. (2012) From psychological imprisonment to intellectual freedom - the different roles that school mathematics can take in student's lives. Paper presented at 12th International Congress on Mathematical Education 8 July - 15 July, 2012, COEX, Seoul, Korea

Boaler, J. (2015) Fluency without fear Research evidence on the best ways to learn math facts, available from https://www.youcubed.org/wpcontent/uploads/2015/03/FluencyWithoutFear-2015.pdf, accessed 27 $7^{\text {th }}$ October 2015 
Boaler, J., \& Greeno, J. G. (2000). Identity, agency, and knowing in mathematics worlds. In J. Boaler (Ed.), Multiple perspectives on mathematics teaching and learning (pp. 171200). Westport, CT: Ablex publishing.

Croft, T. \& Grove, M., (2015). Progression within mathematics degree programmes. In M. Grove, T. Croft, J. Kyle, \& D. Lawson (eds). Transitions in Undergraduate Mathematics Education. Birmingham: University of Birmingham, pp. 173 - 189.

Daskalogianni K., \& Simpson, A. (2002). "Cooling off” - the phenomenon of a problematic transition from school to university. Proceedings of the Second International Conference on Teaching Mathematics at the Undergraduate Level, 103-10. Crete, Greece.

Exley, S. and Ball, S. J. (2013). Neo-liberalism and English education. In Neoliberal Education Reforms: A Critical Analysis, edited by D. Turner and H. Yolcu, 13-31. London: Routledge.

Harel, G., \& Sowder, L. (2007). Toward comprehensive perspectives on the learning and teaching of proof. In F. Lester (Ed.), Second Handbook of Research on Mathematics Teaching and Learning (Vol. 2, pp. 805-842). Charlotte, NC: NCTM/Information Age Publishing.

Hawkes, T., \& Savage, M.D. (2000). Measuring the Mathematics Problem. London: Engineering Council.

Healy, L., \& Hoyles, C. (2000). A study of proof conceptions in algebra. Journal for Research in Mathematics Education, 31(4), 396-428.

Jaworski, B., \& Matthews, J. (2011). Developing teaching of mathematics to first year engineering students. Teaching Mathematics and its Applications, 30(4), 178-185.

Jaworski, B., Robinson, C., Matthews, J., \& Croft, A.C. (2012). An activity theory analysis of teaching goals versus student epistemological positions. International Journal of Technology in Mathematics Education 19(4), 147-152.

Marx, K. (1843) On the Jewish Question, in Karl Marx: Early Writings (1975) L. Colletti (ed) 211-242, Harmondsworth: Penguin,

Marx, K. (1844) Economic and Philosophical Manuscripts, in Karl Marx: Early Writings (1975) L. Colletti (ed) 279-400, Harmondsworth: Penguin

Marx, K. \& Engels, F. (1845) Collected Works Volume 4 (1975) London: Lawrence \& Wishart

Pampaka, M., Williams, J. \& Hutcheson, G. (2012). Measuring students' transition into university and its association with learning outcomes. British Educational Research Journal 38( 6), 1041-1071

Schoenfeld, A. (1994). Reflections on doing and teaching mathematics. In Schoenfeld (Ed.), Mathematical thinking and problem solving (pp. 53-70). Hillsdale, NJ: Erlbaum

Smith, A. (2004). Making Mathematics Count. The Report of Professor Adrian Smith's Inquiry into Post-14 Mathematics Education, The Stationery Office London. http://www.mathsinquiry.org.uk/report/MathsInquiryFinalReport.pdf.

Solomon, Y. (2006). Deficit or difference? The role of students' epistemologies of mathematics in their interactions with proof, Educational Studies in Mathematics 61:3 373-393

Solomon, Y. (2007). Not belonging? What makes a functional learner identity in the undergraduate mathematics community of practice?, Studies in Higher Education 32:1, 79-96

Solomon, Y., Croft, A. \& Lawson, D. (2010). Safety in numbers: mathematics support centres and their derivatives as social learning spaces, Studies in Higher Education $35: 4,421-431$

Solomon, Y., Lawson, D. \& Croft, A. (2011) 'Dealing with “fragile identities”: resistance and refiguring in women mathematics students', Gender and Education 23:5, 565 -58 
Wiliam, D. (2005). Full Report of Research Activities and Results: Students Experiences of Undergraduate Mathematics: R000238564. Swindon: Economic and Social Research Council. Retrieved $23^{\text {rd }}$ October 2015 from http://researchcatalogue.esrc.ac.uk/grants/R000238564/read

Williams, J. (2011). Toward a political economic theory of education: use and exchange values of enhanced labor power, Mind, Culture, and Activity, 18:3, 276 - 292

Williams, J. (2012). Use and exchange value in mathematics education: contemporary CHAT meets Bourdieu’s sociology Educational Studies in Mathematics 80:57-72 